\title{
An Assessment of Antibiotic Drugs Utilization Pattern in Paediatric Population
}

\author{
Avanthi Bandela', Sonika Rathod', Mounika Mullukuntla', Vijay Kumar Guduru², Goverdhan \\ Puchchakayala ${ }^{1, *}$
}

1Department of Clinical Pharmacy, Vaagdevi College of Pharmacy, Kakatiya University, Mahatma Gandhi Memorial Hospital, Warangal, Telangana, INDIA.

${ }^{2}$ Professor of Pediatrics, Mahatma Gandhi Memorial Hospital, Kakatiya Medical College, Warrangal, Telangana, INDIA

\begin{abstract}
Background: The study is to improve the quality of prescribing and may help in overcoming the problems associated with irrational use of antibiotics. Aim: To evaluate antibiotic drugs utilisation in paediatric population. Methods: A prospective observational study was conducted in paediatric department in a tertiary care teaching hospital for a period of 6 months. All the patients who were prescribed with any of antibiotic drug therapy were included in the study and reviewed. Results: Prescribing pattern was observed in 600 subjects during the study period. Antibiotics were prescribed for various conditions like bronchopneumonia (23.16\%), viral pyrexia $(16.16 \%)$, lower respiratory tract infection $(10.16 \%)$, seizures $(8.16 \%)$, acute gastroenteritis $(7 \%)$ and other conditions $(35.33 \%)$. In the included paediatric population, children's were more prone to infections followed by neonates. In our study most frequently used antibiotic drugs were ampicillin, amikacin, cefotaxime, ceftriaxone and amoxiclav. Most often prescribed dosage forms of antibiotic drugs were injection (82\%), syrup (10\%), tablet $(7 \%)$ and capsule (1\%). To identify pathogenic organisms, specimens were collected from $56(9.33 \%)$ of subjects. Commonly used specimens were serum $16(28.57 \%)$, sputum $24(42.85 \%)$, cerebrospinal fluid $7(12.5 \%)$ and other specimens $9(16.07 \%)$. The number of drugs prescribed was found to be with a minimum of 2 and maximum of 5 antibiotic drugs. Conclusion: The treatment regimen given in most of the cases was without performing any culture sensitivity test which may lead to irrational use of antibiotics. Antibiotic resistance leads to a decrease in treatment success, which results in increased morbidity and mortality.
\end{abstract}

Key words: Antibiotic drugs, Paediatric, Prescribing pattern, Rational drug use, Drug utilization evaluation.

\section{INTRODUCTION}

Antibiotics are one of the oldest discovered drugs that combat specific microorganisms like bacteria and fungi. These substances are produced by microorganisms, which at low concentration kill the other microorganisms. ${ }^{1}$ In paediatrics; antibiotics are mostly prescribed as they have higher rates of infections and due to their immature immunity and susceptibility to bacterial infection. $^{2}$

Infections such as diarrhoea, upper respiratory tract infections, acute respiratory tract infections and viral fever are caused by viruses and the large volumes of antibiotics are prescribed. ${ }^{3,4}$ The rational use of drugs means patients receive medications appropriate to their clinical needs, adherence and drug availability in adequate dose for the sufficient duration of time. ${ }^{5,6}$ Antibiotics start combating an infection within few hours of time, but it is also important to complete the whole course of antibiotics to DOI: 10.5530/ijopp.12.4.53 prevent the return of the infection. Stopping the medication before the course has finished increases the risk that the bacteria will become resistant to future treatments. ${ }^{7}$ Common side effects of antibiotics are vomiting, nausea, diarrhoea, bloating and indigestion, abdominal pain, loss of appetite and allergic reactions. ${ }^{8}$ Before starting antibiotic treatment, the paediatrician should ask if appropriate sample have obtained for culture or other microbiological investigations, when indicated in order to establish the specific microbiological diagnosis. ${ }^{9}$ There is vast number of laboratory tests that helps in identify the organism. The tests are broadly
Address for

correspondence:

Dr. Goverdhan Puchchakayala,

Professor and Head, Department of Clinical Pharmacy, Vaagdevi

College of Pharmacy, Warangal,

Telangana, INDIA.

Phone no: +91 8327621533

Email Id: gov_ku@yahoo.co.in

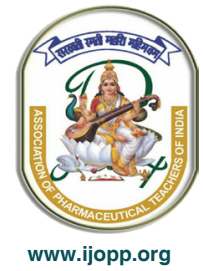


divided into indirect and direct non-culture based and culture based tests, Nucleic Acid Amplification Tests (NAATs), White Cell Count test (WCC), C-reactive Protein (CRP) and also Point of Care (POC) tests. ${ }^{10}$

Antibiotics are not suitable drugs for viral infections. Antibiotics cannot kill viruses as result of viruses have completely different structures and replicate in a very different method than bacteria. Antibiotics cannot destroy viruses as a result of the specifically target the machinery found in bacteria. Since viruses don't contain any of this machinery, the antibiotic doesn't have a target to attack. ${ }^{11}$ Antibiotics for the viral infection is highly misused medicine. The standard of treatment needs prescribing to be acceptable, safe and effective and therefore the aim is to realize clinical profit. ${ }^{12}$

Antibiotic consumption is directly related to the antibiotic resistance rates of common bacteria. ${ }^{13}$ Antibiotics are usually against the bacterial growth, but when the microbes become less sensitive or resistant, higher concentration of same drug is needed to have an effect. ${ }^{14}$ Antibiotic resistance occurs when a drug loses its ability to inhibit bacterial growth effectively. ${ }^{15}$ Antibiotic resistance leads to a decrease in treatment success, which results in increased mortality and morbidity. ${ }^{16}$

The main aim of the study is to evaluate the prescribing pattern of antibiotics in paediatric department of MGM Hospital located in Warangal, Telangana, India. The significance of the study is to improve the quality of prescribing and may help in overcoming the problems associated with irrational use of antibiotics. To optimize antibiotic therapy, by promoting rational use of antibiotics, dosing, route and duration of therapy in order to improve clinical care or prevent infections.

\section{MATERIALS AND METHODS}

\section{Study design}

This is a prospective observational study which was conducted for 6 months in Department of Paediatric, in Mahatma Gandhi Memorial Hospital, Warangal, Telangana, India.

\section{Inclusion criteria}

All the patients who were prescribed with antibiotics in the paediatric ward were included in the study. Patient's both genders, age 0-12 years were included.

\section{Exclusion criteria}

The paediatric out patients and age above 12 years were excluded.

Indian Journal of Pharmacy Practice, Vol 12, Issue 4, Oct-Dec, 2019

\section{Methods}

The study protocol and informed consent was reviewed and approved by institutional ethical committee MGM/ VCOP/PHARMD/V/019/2017. Informed consent was obtained from all the care takers of patient by explaining them in their language about the process of work. Study was divided in to three phases. Phase-1: primary study to identify the outlook of work and to conclude various paediatric diseases, Phase-2: literature review, preparation of data entry format and collection of cases and Phase-3: data analysis and identification of plan of antibiotic use.

A total of 600 cases were studied in paediatric inpatient department, which has complete information as per inclusion criteria. The relevant data were collected in specially designed proforma, which contained patient demographics, diagnosis, investigations, drug details and information from the prescriber regarding the indication for prescribing antibiotic agent, suspecting organism underlying infection, duration of therapy.

\section{Statistical analysis}

The data was subjected to descriptive analysis using Microsoft Excel.

\section{RESULTS}

\section{Basic demographic data}

Figure 1 reveals a total of 600 patients were enrolled from paediatric department. Majority of the study subjects who participated in the study were belonging to the age group of children (2-12 years) 328 followed by infants (1 month -2 years) 268 and neonates (0-30 days) 04 .

Figure 2 shows the more number of males 347 (57.10\%) was found to be effected to infections as compared to females 253 (42.90\%).

\section{Frequency of antibiotics used for particular indication and duration of antibiotic therapy}

Table 1 shows out of 600 cases, patients with different conditions such as acute gastroenteritis, bronchopneumonia, lower respiratory tract infection, seizures and other diseases were enrolled. Out of all the subjects commonly observed clinical conditions were bronchopneumonia 139 (23.16\%), lower respiratory tract infections $61(10.16 \%)$, viral pyrexia $97(16.16 \%)$, seizures $49(8.16 \%)$, acute gastroenteritis $42(7 \%)$ and other conditions 212 (35.33\%). Number of antibiotics prescribed for different indications and duration of therapy was shown in days.

Table 2 shows that frequency and cumulative frequency, 
Table 1: Frequency of antibiotics used forparticular indication and duration of antibiotic therapy.

\begin{tabular}{|c|c|c|c|c|c|c|c|c|c|c|}
\hline \multirow[t]{2}{*}{ SI. No. } & \multirow[t]{2}{*}{ Disease } & \multirow[t]{2}{*}{$\begin{array}{l}\text { Number of } \\
\text { patients }\end{array}$} & \multirow[t]{2}{*}{$\begin{array}{l}\text { Percentage of } \\
\text { disease }\end{array}$} & \multicolumn{3}{|c|}{$\begin{array}{c}\text { Number of antibiotics } \\
\text { used }\end{array}$} & \multicolumn{4}{|c|}{$\begin{array}{l}\text { Duration of antibiotic therapy } \\
\text { (in days) }\end{array}$} \\
\hline & & & & 1 & 2 & $>2$ & $1-3$ & 4-6 & $7-9$ & $>10$ \\
\hline 1 & AcuteGE & 42 & $7 \%$ & 21 & 16 & 5 & 7 & 20 & 10 & 5 \\
\hline 2 & Acute GN & 10 & $1.66 \%$ & 9 & 0 & 1 & 0 & 7 & 3 & 0 \\
\hline 3 & Anaemia & 21 & $3.5 \%$ & 11 & 4 & 6 & 6 & 7 & 5 & 3 \\
\hline 4 & Asthma & 7 & $1.16 \%$ & 2 & 3 & 2 & 1 & 3 & 2 & 1 \\
\hline 5 & Bronchiolitis & 13 & $2.16 \%$ & 8 & 3 & 2 & 4 & 2 & 3 & 4 \\
\hline 6 & Bronchopneumonia & 139 & $23.16 \%$ & 9 & 99 & 31 & 25 & 65 & 40 & 9 \\
\hline 7 & LRTI & 61 & $10.16 \%$ & 16 & 31 & 14 & 15 & 28 & 8 & 10 \\
\hline 8 & Malaria & 14 & $2.33 \%$ & 9 & 3 & 2 & 5 & 4 & 2 & 3 \\
\hline 9 & Meningitis & 11 & $1.83 \%$ & 0 & 9 & 2 & 5 & 0 & 2 & 4 \\
\hline 10 & Seizures & 49 & $8.16 \%$ & 29 & 17 & 3 & 25 & 15 & 2 & 7 \\
\hline 11 & Septicaemia & 22 & $3.66 \%$ & 1 & 15 & 6 & 5 & 5 & 7 & 5 \\
\hline 12 & URTI & 18 & $3 \%$ & 9 & 6 & 3 & 4 & 11 & 2 & 1 \\
\hline 13 & UTI & 24 & $4 \%$ & 12 & 10 & 2 & 3 & 10 & 8 & 3 \\
\hline 14 & Viralpyrexia & 97 & $16.16 \%$ & 30 & 47 & 20 & 26 & 36 & 25 & 10 \\
\hline \multirow[t]{2}{*}{15} & Other diseases & 72 & $12 \%$ & 22 & 28 & 22 & 13 & 26 & 18 & 15 \\
\hline & Total & 600 & $100 \%$ & 188 & 291 & 121 & 144 & 239 & 137 & 80 \\
\hline
\end{tabular}

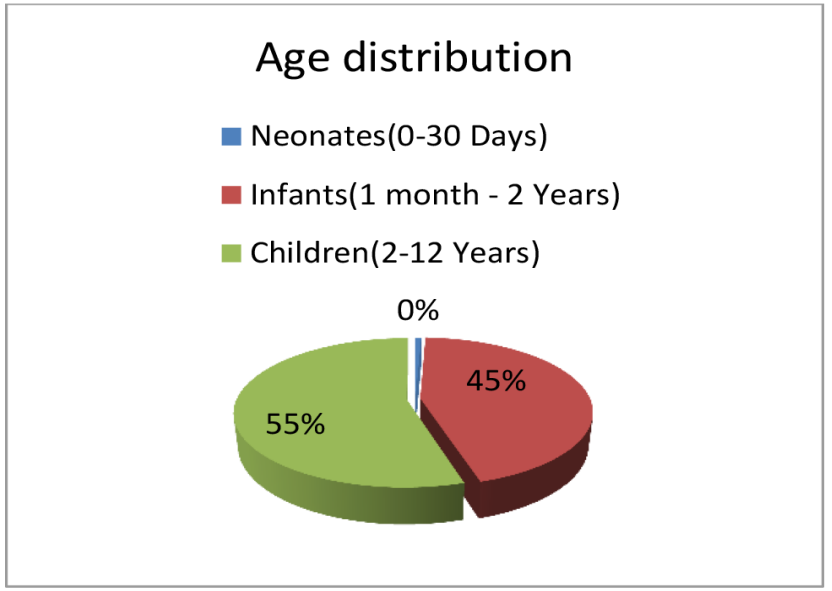

Figure 1: Distribution of age groups.

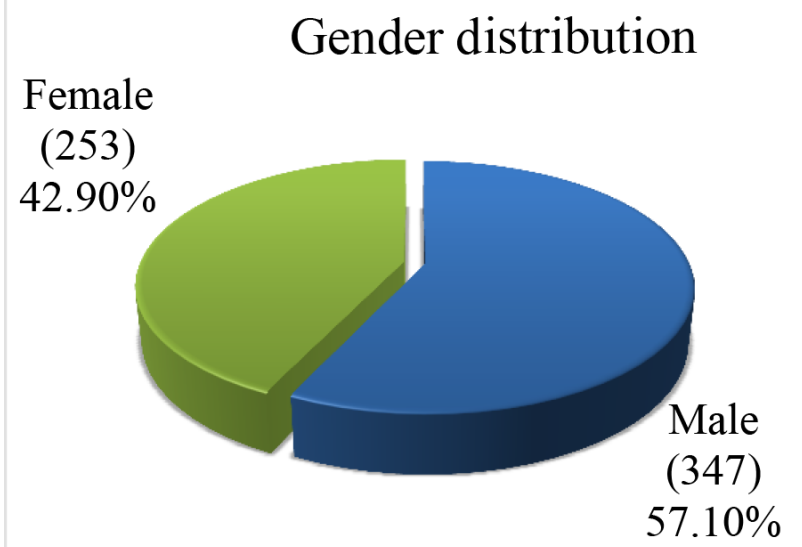

Figure 2: Gender wise distribution of paediatric population.
Table 2: Duration of therapy of paediatric patients.

\begin{tabular}{|c|c|c|c|c|}
\hline 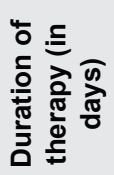 & 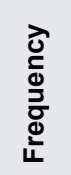 & $\underset{\substack{0 \\
\frac{0}{0}}}{\stackrel{0}{0}}$ & 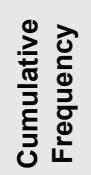 & 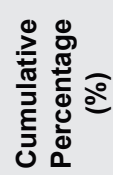 \\
\hline $1-3$ & 144 & 24 & 144 & 24 \\
\hline $4-6$ & 239 & 39.83 & 383 & 63.83 \\
\hline $7-9$ & 137 & 22.83 & 520 & 86.66 \\
\hline$>10$ & 80 & 13.33 & 600 & 100 \\
\hline
\end{tabular}

percent and cumulative percent of the patient's duration of therapy. Patients were administered antibiotics for an duration of 4-6 days in 239 subjects, 1-3 days in 144 subjects, 7-9 days in 137 subjects and more than 10 days in 80 subjects.

Figure 3 reveals that Antibiotics can be given as single drug or in a combination therapy. Our study shows many of subjects were prescribed with two antibiotics in 297 subjects, more than two antibiotics in 121 subjects and a single or 1 antibiotic prescribed in 188 subjects.

\section{Number of antibiotics prescribed and dosage form}

Table 3 shows that out of 600 subjects, majority of patients were prescribed with ampoxin 327 (30.11\%), amikacin 241 (22.19\%), cefixime 165 (15.19\%), ampicillin $111(10.22 \%)$, Ceftriaxone 99 (9.11\%), cephalexin 47 $(4.32 \%)$ and other antibiotics $96(8.86 \%)$ and shows the different types of dosage form prescribed.

Indian Journal of Pharmacy Practice, Vol 12, Issue 4, Oct-Dec, 2019 


\begin{tabular}{|c|c|c|c|c|c|c|c|}
\hline \multirow[t]{2}{*}{ SI. No } & \multirow[t]{2}{*}{ Name of antibiotic } & \multirow{2}{*}{$\begin{array}{l}\text { Number of } \\
\text { patients }\end{array}$} & \multirow{2}{*}{$\begin{array}{l}\text { Percentage } \\
\text { of drugs }\end{array}$} & \multicolumn{4}{|c|}{ Dosage form } \\
\hline & & & & Injection & Syrup & Tablet & Capsule \\
\hline 1 & Albendazole & 9 & $0.82 \%$ & 0 & 5 & 4 & 0 \\
\hline 2 & Amikacin & 241 & $22.19 \%$ & 241 & 0 & 0 & 0 \\
\hline 3 & Amoxicillin & 7 & $0.64 \%$ & 0 & 5 & 0 & 2 \\
\hline 4 & Ampicillin & 111 & $10.22 \%$ & 7 & 69 & 35 & 0 \\
\hline 5 & Ampoxin & 327 & $30.11 \%$ & 327 & 0 & 0 & 0 \\
\hline 6 & Azithromycin & 28 & $2.57 \%$ & 28 & 0 & 0 & 0 \\
\hline 7 & Cefotaxime & 7 & $0.64 \%$ & 2 & 1 & 4 & 0 \\
\hline 8 & Cefixime & 165 & $15.19 \%$ & 164 & 1 & 0 & 0 \\
\hline 9 & Cephalexin & 47 & $4.32 \%$ & 3 & 28 & 16 & 0 \\
\hline 10 & Ceftriaxone & 99 & $9.11 \%$ & 99 & 0 & 0 & 0 \\
\hline 11 & Clindamycin & 8 & $0.73 \%$ & 3 & 0 & 2 & 3 \\
\hline 12 & Erythromycin & 14 & $1.28 \%$ & 0 & 0 & 14 & 0 \\
\hline 13 & Metronidazole & 14 & $1.28 \%$ & 12 & 1 & 1 & 0 \\
\hline 14 & Streptomycin & 3 & $0.27 \%$ & 4 & 0 & 0 & 0 \\
\hline 15 & Vancomycin & 3 & $0.27 \%$ & 3 & 0 & 0 & 0 \\
\hline \multirow[t]{2}{*}{16} & Other drugs & 3 & $0.27 \%$ & 0 & 1 & 2 & 0 \\
\hline & Total & 1086 & $100 \%$ & $893(82 \%)$ & $110(10 \%)$ & $78(7 \%)$ & $5(1 \%)$ \\
\hline
\end{tabular}

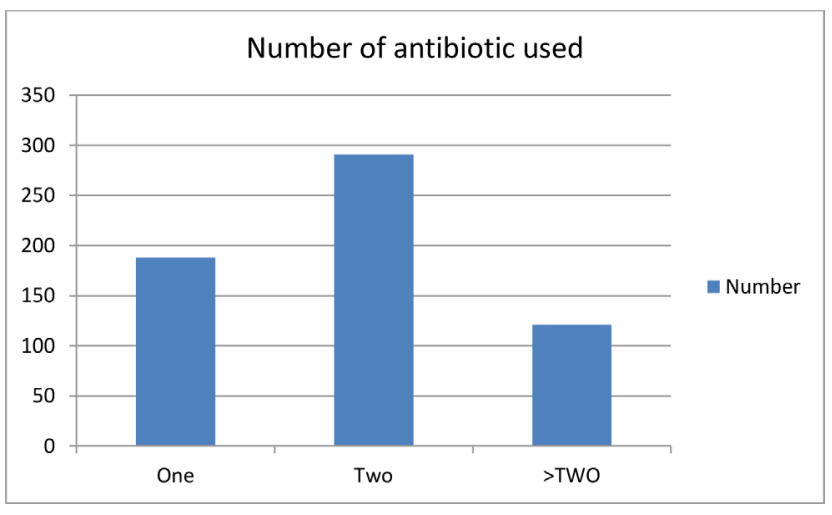

Figure 3: Number of antibiotics prescribed.

Table 4 reveals the class of antibiotics prescribed. Majority of the subjects were prescribed with penicillins 445 (40.97\%), cephalosporins 318 (29.28\%), aminoglycosides $244(22.46 \%)$ followed by Macrolides 50 (4.60\%) and others $29(2.67 \%)$.

Figure 4 reveals that a different types of dosage forms, among that, injections $893(82.13 \%$ ) are more commonly used dosage forms than syrups $110(10.12 \%)$ followed by tablets $78(7.18 \%)$ and capsules $05(0.46 \%)$.

\section{Number of Specimens taken for culture sensitivity test}

Figure 5 shows the Out of 600 cases, specimens were collected for culture test in only 56 patients to identify pathogenic organisms as serum $16(28.57 \%)$, urine 4 (7.14\%), sputum $24(42.85 \%)$, stool $5(8.92 \%)$ and Indian Journal of Pharmacy Practice, Vol 12, Issue 4, Oct-Dec, 2019

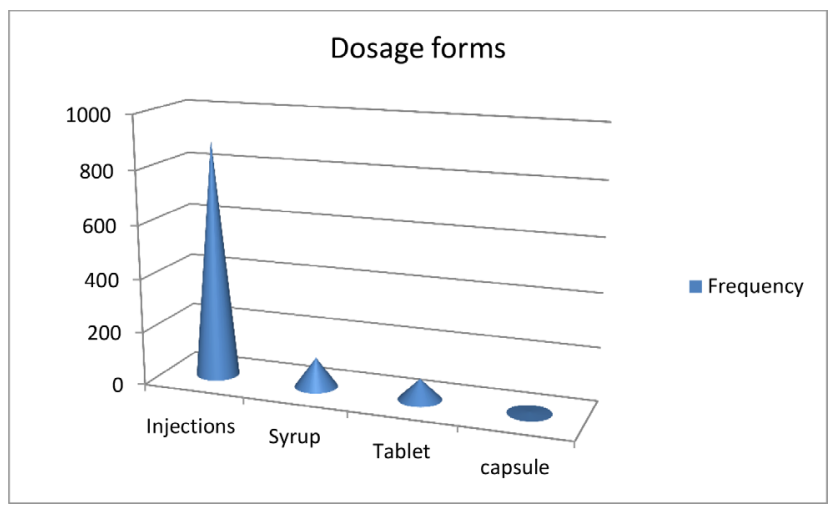

Figure 4: Dosage Forms.

Specimens used for organism isolation
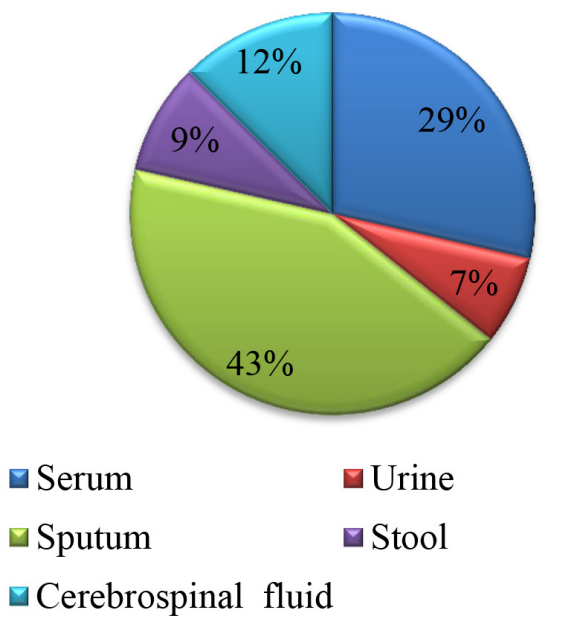

Figure 5: Specimens used for organism isolation. 


\begin{tabular}{|c|c|c|}
\hline Antibiotic Class & Frequency $(\mathrm{N})$ & Percentage (\%) \\
\hline Penicillin & 445 & 40.97 \\
\hline Cephalosporin & 318 & 29.28 \\
\hline Aminoglycosides & 244 & 22.46 \\
\hline Macrolides & 50 & 4.60 \\
\hline Nitroimidazoles & 23 & 2.11 \\
\hline Glycopeptides & 3 & 0.27 \\
\hline Other drugs & 3 & 0.27 \\
\hline Total & 1086 & 100 \\
\hline
\end{tabular}

Table 5: Culture report of the patients.

\begin{tabular}{|c|c|c|c|c|}
\hline $\begin{array}{l}0 \\
\frac{0}{3} \\
\frac{ \pm}{3} \\
\text { 능 }\end{array}$ & $\begin{array}{l}\text { তे } \\
\frac{0}{0} \\
\frac{0}{0} \\
\text { 닌 }\end{array}$ & 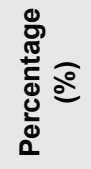 & 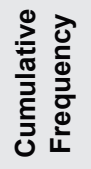 & 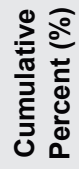 \\
\hline Positive & 20 & 35.71 & 20 & 35.71 \\
\hline Negative & 36 & 64.28 & 56 & 100 \\
\hline
\end{tabular}

cerebrospinal fluid 7 (12.5\%) samples. Preferably serum and sputum were collected in large numbers.

Table 5 shows the culture report of the patients in frequency, cumulative frequency and percent and cumulative percent. Out of 600 patients, specimens were collected for culture report in only 56 patients. From the above data 20 specimens showed positive result and 36 specimens showed negative result.

\section{DISCUSSION}

Antibiotics are commonly used for the treatment of bacterial infections. The reviewing of the prescription and rational prescribing of the drugs is necessary to improve the therapeutic efficacy and to decrease the adverse effects of the drugs.

Six hundred patients were enrolled in the study where 347 male patients and 253 female patients. Which was similar to study performed in Coimbatore by Chitra et al. ${ }^{17}$ the study on gender categorization had revealed that the overall study population was predominantly male population.

In our study majority of antibiotics received patients belong to the age group of children (2-12 years) followed by infants ( 1 month - 2 years) and neonates (0-30 days). This was supported by the study conducted in Gujarat by Sondarva et al. ${ }^{18}$ who concluded that out of 255 patients enrolled, the majority of patients were 5 years.

Out of 600 cases majority of the patients were diagnosed with bronchopneumonia 139 (23.16\%), viral pyrexia 97 $(16.16 \%)$, lower respiratory tract infection $61(10.16 \%)$, seizures 49 (8.16\%), acute gastroenteritis $42(7 \%)$ and other conditions $212(35.33 \%)$. The longest duration of antibiotic therapy was observed for 4-6 days and shortest was for 7-9 days. This was comparable to the study conducted in Kingdom of Saudi Arabia by Kousalya et al. ${ }^{19}$ where majority of children were diagnosed with enteric fever and urinary tract infection (21\%), followed by upper respiratory tract infection (18\%). The mean value of hospitalization length in children with prescribed antibiotics was 5 days.

Most frequently prescribed antibiotics for empirical therapy were penicillin's 445 (40.97\%), aminoglycosides $244(22.74 \%)$, cephalosporin's $318(29.28 \%)$ and Macrolides 50 (4.60\%) and other antibiotics 29 (2.67\%). This was slightly to similar to the study conducted in Egypt, Mona et al. ${ }^{20}$ who concluded that the most frequently prescribed antibiotics for empirical therapy were quinolones (45\%), followed by broad spectrum penicillin's (25\%) and cephalosporin's (10\%).

Majority of the patients were prescribed with ampoxin (ampicillin + cloxacillin) 327 (30.11\%), amikacin 241 (22.19\%), cefixime 165 (15.19), ampicillin 111 (10.22\%), ceftriaxone 99 (9.11\%) followed by cephalexin $47(4.32 \%)$ and other antibiotics $96(8.86 \%)$. This study was similar to the study conducted in guwahati by choudhury et al. ${ }^{21}$ where maximum number of antibiotics prescribed were amoxicillin + clavulanic acid $35 \%$, followed by ceftriaxone $29 \%$, amikacin $17 \%$, Cefotaxime + sulbactum $12 \%$, Vancomycin 2\% and tobramycin 1\%.

Patients who were prescribed with two antibiotics were about $(48.5 \%)$ patients, one antibiotic were prescribed in $(31.33 \%)$ patients and greater than two antibiotics were prescribed in only $(20.16 \%)$ patients. This data is complementary to the study done in Tamil Nadu by Shamshy et al..$^{22}$ where majority of patients $(54.58 \%)$ were prescribed at least one antibiotic, two antibiotics were prescribed in $(28.57 \%)$, three antibiotics were prescribed in $(15.02 \%)$ and four antibiotics were prescribed in only $(1.83 \%)$ cases.

Frequently used dosage forms of antibiotics were as injections $893(82 \%)$, syrups $110(10 \%)$, tablets $78(7 \%)$ and capsules $5(1 \%)$. This study is identical to the three studies carried out by Mona et al. Chitra et al. and Megha et $a l^{23}$

On the basis of data evaluation $91 \%$ of antibiotic prescriptions were treated on a clinical basis, without performing any microbiological tests, this is supported by 
study conducted in Kingdom of Saudi Arabia by Kousalya Prabahar et al. over $50 \%$ of antibiotic prescriptions were started on a clinical basis, without confirmation of a bacterial infections.

Over 600 patients clinically diagnosed with infectious diseases, treated with antibiotics, specimens were taken for culture test in only 56 patients for identification of pathogenic organisms' sputum (43\%), serum (29\%), cerebrospinal fluid $(12 \%)$, stool $(9 \%)$ and urine $(7 \%)$. among 56 specimens only 20 specimens showed positive result and 36 specimens showed negative result. Which was similar to study done in Tamil Nadu by Shamshy et al. for detection of organisms, specimens were collected in only 14 cases out of 273 patients. Patient's blood culture was $2.56 \%$, sputum $0.73 \%$, urine $1.46 \%$ and other pus $0.37 \%$. In those only six specimens showed positive culture result.

\section{CONCLUSION}

Antibiotic prescribing pattern was effective in most of the subjects. The report on sensitivity pattern was helpful to select the appropriate antibiotics to patient. The rational use of antibiotics is one of the main contributes to control worldwide emergence of antibiotic resistance and side effects. The study concludes that the treatment regimen given in most of the cases is without performing any culture sensitivity test which may lead to irrational use of antibiotics and develop resistance. In most cases children were admitted very sick and clinicians justify empirical antibiotics in such suffered life-threatening infections.

\section{ACKNOWLEDGEMENT}

I would like to thank my parents and friends Mr. K Vinay Kumar, P Prashanth Reddy and Miss. CH Tejaswi Reddy for their support in completion of the project.

\section{CONFLICT OF INTEREST}

The authors declare no conflict of interest

\section{ABBREVIATIONS}

NAATs: Nucleic Acid Amplification Tests; WCC: White Cell Count; CRP: C-Reactive Protein; POC: Point of Care; Acute GE: Acute Gastroenteritis; Acute GN: Acute Glomerulonephritis; LRTI: Lower Respiratory Tract Infection; URTI: Upper Respiratory Tract Infection; UTI: Urinary Tract Infection

\section{SUMMARY}

The main challenges in prescription of antibiotics are to achieve a rational and appropriate use of antibiotics and to recognize their potential side effects. Empirical therapy and antibacterial usage for viral infection can be reduced by the availability of rapid diagnostic method to differentiate between viral and bacterial infection.

\section{REFERENCES}

1. Tripathi KD. Essentials of medical pharmacology sixth edition, Jaypee Brothers Medical Publishers (P) Ltd. 2008;667-81.

2. Sharland M. SACAR paediatric subgroup. The use of antibacterial in children. A report of the Specialist Advisory Committee on Antimicrobial Resistance (SACAR) Paediatric subgroup. J Antimicrob Chemother. 2007;60(supply_1):i15-26.

3. Kumar R, Indira K, Rizvi A, Rizvi T, Jayaseelan L, et al. Antibiotic prescribing practices in primary and secondary healthcare facilities in UP, India. J Clin Pharm Ther. 2008;33(6):625-34.

4. Gha P, et al. Disorders of respiratory system. Essential paediatrics. $7^{\text {th }}$ edition. 2009;351-2.

5. World Health Organization. Promoting rational use of medicines: core components. Geneva: World Health Organization. 2002. Promoting rational use of medicines; Core Components: WHO Policy Perspectives on Medicines. 2002;(5).

6. Gupta U, et al. A Baseline Survey of Drug Use in a Delhi Hospital. INRUD News. 1998;8(2):21.

7. Antibiotics: uses, resistance and side effects-medical news today. Available form: http://www.medicalnewstoday.com/articles/10278.php.

8. Antibiotics side effects, resistance types and drug-emedicine health. Available form: http://www.emedicinehealth.com/antibiotics/article em.htm.

9. Matas L, Mendez M, Rodrigo C, Ausina V. Diagnosis of streptococcal pharyngitis. Enferm Infecc Microbiol Clin. 2008;26(suppl 13):14-8.

10. Povoa P. C- Reactive Protein: A valuable marker of sepsis. Intensive Care Med 2002;28(3):235-43.

11. Microbiology 101: Why antibiotics don't kill viruses. Available form: http://www. drbarrydworkin.com/articles/medicine/infectious-disease-articles/microbiology101-why-antibiotics-dont -kill-viruses/.

12. Martin RM. When to use a new drug. Aust Prescr. 1998;21(3):67-9. Available form: http://www.researchgate.net/publication/283963323-when-to-use-a-newdrug.

13. Antimicrobial resistance: Global report on surveillance. 2014-WHO. Available form: http://www.who.int/drugresistance/documents/surveillancereport/en/.

14. Levy SB, Chadwick DJ, Goode J, et al. Antibiotic resistance: An ecological imbalance InCiba Foundation Symposium. 2007;207(1-9):1-14.

15. Overview of bacteria - Infectious Disease - Merck manuals. Available form: http://www.merckmanuals.com/home/infections/bacterial infections/overview of bacteria.

16. Hashemi S, Nasrollah A, Rajabi M. Irrational antibiotic prescribing; a local issue or Global concern. EXCIL Journal. 2013;12:384-95.

17. Chitra B, Panicker S. Drug Utilization Evaluation of Antibiotics at a Tertiary Care Hospital. International Journal of Pharmacy and Pharmaceutical Research. 2016;7(3):350-9.

18. Sondarva DB, Kubavat AR, Patel BS, Mistry VR . Utilization of Antimicrobial Agents in Paediatric Indoor Patients of Pneumonia at Tertiary Care Hospital. World Journal of Pharmacy and Pharmaceutical Sciences. 2015;4(2):301-10.

19. Kousalya P, Sikharam D, Swetha B, Padmasani LN. Antibiotic Utilization Pattern in Paediatrics in a Tertiary Care Teaching Hospital. Asian Journal of Pharmaceutics. 2017;11(1):S230-4

20. Mona MA, ELMaraghy AA, Engy WA. Study of prescription pattern of antibiotics in treating lower respiratory tract infections at Sohag Chest Hospital. Egyptian Journal of Chest Diseases and Tuberculosis. 2016;65(1):143-55.

21. Choudhury DK, Bezbaruah BK, et al. Antibiotic prescriptions pattern in paediatric in-patient Department Gauhati Medical College and Hospital, Guwahati. Journal of Applied Pharmaceutical Science. 2013;3(08);144-8.

22. Shamshy K, Mufida BL, Perumal P. Drug Utilization of Antimicrobial Drug in Paediatrics Population in a tertiary care hospital in Erode, Tamil Nadu, India. International Journal of PharmTech Research CODEN (USA). 2011;3(3):1530-6.

23. Megha S, Anna D, Ashish P. Antibiotic Prescribing among Paediatric In patients with Potential Infections in Two Private Sector Hospitals in Central India. PLoS One. 2015;10(11):e0142317. 